\title{
Impact of a behavioural sleep intervention on symptoms and sleep in children with attention deficit hyperactivity disorder, and parental mental health: randomised controlled trial
}

\author{
(c) (1) $(9)$ OPEN ACCESS
}

\author{
Harriet Hiscock associate professor ${ }^{12}$, Emma Sciberras clinical psychologist ${ }^{12}$, Fiona Mensah \\ statistician $^{123}$, Bibi Gerner project officer ${ }^{12}$, Daryl Efron paediatrician ${ }^{12}$, Sonia Khano research \\ assistant $^{12}$, Frank Oberklaid professor ${ }^{12}$
}

${ }^{1}$ Murdoch Childrens Research Institute, Centre for Community Child Health, Royal Children's Hospital, Parkville VIC 3052 , Australia; ${ }^{2}$ Department of Paediatrics, University of Melbourne, Melbourne, VIC, Australia; ${ }^{3}$ Murdoch Childrens Research Institute, Clinical Epidemiology and Biostatistics Unit, Royal Children's Hospital, Parkville VIC, Australia

\begin{abstract}
Objective To examine whether behavioural strategies designed to improve children's sleep problems could also improve the symptoms, behaviour, daily functioning, and working memory of children with attention deficit hyperactivity disorder (ADHD) and the mental health of their parents

Design Randomised controlled trial.

Setting 21 general paediatric practices in Victoria, Australia.

Participants 244 children aged 5-12 years with ADHD attending the practices between 2010 and 2012 .

Intervention Sleep hygiene practices and standardised behavioural strategies delivered by trained psychologists or trainee paediatricians during two fortnightly consultations and a follow-up telephone call. Children in the control group received usual clinical care.
\end{abstract}

Main outcome measures At three and six months after randomisation: severity of ADHD symptoms (parent and teacher ADHD rating scale IV-primary outcome), sleep problems (parent reported severity, children's sleep habits questionnaire, actigraphy), behaviour (strengths and difficulties questionnaire), quality of life (pediatric quality of life inventory 4.0), daily functioning (daily parent rating of evening and morning behavior), working memory (working memory test battery for children, six months only), and parent mental health (depression anxiety stress scales).

Results Intervention compared with control families reported a greater decrease in ADHD symptoms at three and six months (adjusted mean difference for change in symptom severity $-2.9,95 \%$ confidence interval -5.5 to $-0.3, P=0.03$, effect size -0.3 , and $-3.7,-6.1$ to $-1.2, P=0.004$, effect size -0.4 , respectively). Compared with control children, intervention children had fewer moderate-severe sleep problems at three months ( $56 \%$ v $30 \%$; adjusted odds ratio $0.30,95 \%$ confidence interval 0.16 to $0.59 ; \mathrm{P}<0.001)$ and six months $(46 \% \vee 34 \% ; 0.58,0.32$ to 1.0 ; $\mathrm{P}=0.07)$. At three months this equated to a reduction in absolute risk of $25.7 \%$ (95\% confidence interval $14.1 \%$ to $37.3 \%$ ) and an estimated number needed to treat of 3.9. At six months the number needed to treat was 7.8. Approximately a half to one third of the beneficial effect of the intervention on ADHD symptoms was mediated through improved sleep, at three and six months, respectively. Intervention families reported greater improvements in all other child and family outcomes except parental mental health. Teachers reported improved behaviour of the children at three and six months. Working memory (backwards digit recall) was higher in the intervention children compared with control children at six months. Daily sleep duration measured by actigraphy tended to be higher in the intervention children at three months (mean difference 10.9 minutes, $95 \%$ confidence interval -19.0 to 40.8 minutes, effect size 0.2 ) and six months (9.9 minutes, -16.3 to 36.1 minutes, effect size 0.3 ); however, this measure was only completed by a subset of children ( $n=54$ at three months and $n=37$ at six months).

Conclusions A brief behavioural sleep intervention modestly improves the severity of ADHD symptoms in a community sample of children with ADHD, most of whom were taking stimulant medications. The intervention also improved the children's sleep, behaviour, quality of life, and 
functioning, with most benefits sustained to six months post-intervention. The intervention may be suitable for use in primary and secondary care.

Trial registration Current Controlled Trials ISRCTN68819261.

\section{Introduction}

Attention deficit hyperactivity disorder (ADHD) affects approximately $5 \%$ of children and adolescents ${ }^{1}$ and is characterised by pervasive, developmentally inappropriate levels of inattention, impulsivity, and hyperactivity. Compared with healthy peers, children with ADHD are at increased risk of academic underachievement, ${ }^{2}$ drop out from school, ${ }^{2}$ risk taking behaviours, ${ }^{3}$ and psychiatric difficulties. ${ }^{4}$ Annual societal costs of ADHD (healthcare, education, justice) in the United States are estimated at \$143-266bn.

Although stimulants are effective for treating the symptoms of inattention and impulsivity, reliance on them in children with ADHD remains of concern. Although most experts agree that psychosocial interventions for ADHD can be effective, doubts have been raised about the magnitude of treatment effects, as small to moderate effects have been found for parent reported outcomes but little effect has been shown using blinded (for example, teacher report) outcomes. ${ }^{6}$ In addition, most psychosocial interventions are long and intense, precluding their use by a primary care workforce.

We have previously documented the benefits of brief behavioural sleep interventions in children without $\mathrm{ADHD}^{7}$ and the high prevalence of sleep problems in children with the disorder. ${ }^{8}$ These sleep problems are usually behavioural ${ }^{89}$ and include difficulties with both initiating (for example, sleep onset association disorder) and maintaining sleep. ${ }^{8}$ Sleep problems are thought to be common in children with ADHD for several reasons, including possible shared neurobiological pathways involving areas of the cortex responsible for regulation or arousal, use of stimulant medications that may exacerbate the delay in sleep onset, presence of comorbid mental health disorders (for example, anxiety associated with insomnia), and poor sleep practices. ${ }^{10}$ These sleep problems are associated with poorer behaviour, quality of life, daily functioning, and school attendance, over and above the impact of ADHD alone. ${ }^{8}$ Parents of children with ADHD and sleep problems experience poorer mental health and are more likely to be late for work. ${ }^{8}$ Successful treatment of sleep problems has real potential to improve child and family outcomes. We tested a novel approach: whether a brief sleep intervention for children with both ADHD and sleep problems might have lasting benefits not only on sleep but on the ADHD itself.

No randomised controlled trials have evaluated the impact of behavioural sleep interventions in children with ADHD. ${ }^{10}$ In 2008 we developed and piloted a behavioural sleep intervention programme for children with ADHD and moderate-severe sleep problems $(n=27)$. The programme resulted in a reduction in sleep problems, and children also tended to show improved functioning and psychosocial quality of life. ${ }^{11}$

We determined the efficacy of this programme in reducing the severity of ADHD symptoms (primary outcome), sleep problems, behaviour, quality of life, daily functioning, and working memory (backwards digit recall) in children, as well the mental health and work attendance of their parents. We hypothesised that a behavioural sleep intervention would improve all these outcomes.

\section{Methods \\ Design and setting}

We have reported our trial protocol previously. ${ }^{12}$ Briefly, the Sleeping Sound with ADHD study is a randomised controlled trial of a behavioural sleep intervention compared with usual clinical care for children with ADHD and sleep problems.

\section{Eligibility and recruitment}

Paediatricians $(n=50)$ from 21 private and public practices across the state of Victoria, Australia, identified families with a child aged 5 to 12 years who they had seen within the past year with a diagnosis of ADHD. We sent the families a letter describing the study and saying that if they did not decline, we would telephone them to explain the study further (that is, the "opt out" approach). After two weeks the paediatricians provided the research team with contact details of families who had not declined. We telephoned these families to further assess eligibility criteria and ascertain their interest in participating in the study. Parents were eligible if their child met the criteria of the Diagnostic and Statistical Manual of Mental Disorders, fourth revision, for ADHD—-that is, parents rated at least six inattentive or six hyperactivity or impulsivity symptoms as being present "often" or "very often" on the ADHD rating scale IV, ${ }^{13}$ with symptom duration of at least six months, onset before age 7 years, and cross situational impairment in two or more of home, school, or social settings ${ }^{14}$; had parent reported moderate to severe sleep problems ${ }^{8}$; and met the American Academy of Sleep Medicine ${ }^{15}$ diagnostic criteria for at least one sleep disorder (for example, sleep onset association disorder, limit setting disorder, delayed sleep phase, or idiopathic or psychophysiological insomnia) or anxiety leading to insomnia.

We excluded families if the child was receiving specialised sleep assistance from a psychologist or a sleep clinic, or had a serious medical condition (for example, severe cerebral palsy), intellectual disability (paediatrician record of IQ $<70$ ), or suspected obstructive sleep apnoea assessed using the corresponding subscale from the children's sleep habits questionnaire, ${ }^{16}$ and their parents had insufficient English to complete surveys. We posted eligible families an information sheet, consent form, baseline survey, and prepaid envelope for reply.

\section{Randomisation and masking}

A statistician who was not involved with the study generated a randomisation schedule using a computerised random number sequence. Assignment was in a ratio of 1:1 intervention to usual care, stratified by the child's sex. Varying block sizes of 2, 4, and 6 were used to ensure balance between the trial arms and within strata. Sealed opaque envelopes were used to conceal allocation from the families and researchers until consent for randomisation was obtained. On receipt of a completed consent form and baseline survey, a research assistant not involved with the study randomised families to either the intervention group or the usual care (control) group.

Intervention and control families were then telephoned to complete a diagnostic interview (anxiety disorders interview schedule for children IV), ${ }^{17}$ assessing internalising and externalising behavioural comorbidities. Families in the control group could access usual care from their child's paediatrician, which did not routinely involve the assessment and management of sleep problems ${ }^{8}$ but typically included reviews of progress every six months, growth and blood pressure, and prescribing of medications where required. After the parents had provided 
consent, we posted a baseline survey to the child's teacher to complete. The research team did not inform the children's paediatricians or teachers of the child's group allocation, although the families may have chosen to do so.

\section{Intervention}

Families in the intervention group were offered two face to face, fortnightly consultations about sleep with a trained clinician (five psychologists; four with 1-4 years of clinical experience and one with 10 years, or a trainee consultant paediatrician with four years of paediatric clinical experience) at their paediatrician's office, the hospital clinic, or home. Families were offered one follow-up telephone call two weeks later. The clinicians' training consisted of two three hour sessions, conducted by $\mathrm{HH}$ and ES, and included information on normal sleep, sleep cycles, sleep cues, sleep hygiene (that is, set bed time, bedtime routines, keeping the bedroom media-free, and avoiding caffeine consumption after $3 \mathrm{pm}$ ), and standard management strategies for behaviour known to be effective in typically developing children ${ }^{718}$; details have been published previously. ${ }^{11}$ None of the clinicians had received specialised training in paediatric sleep management before the trial.

At the first consultation, the clinician assessed the child's sleep problem, elicited parent goals for sleep management, provided information about normal sleep, sleep cycles, and sleep hygiene strategies, and formulated a behavioural sleep management plan tailored to the child's sleep problem. For example, limit setting disorder was managed by ignoring child protests and rewarding compliance with bedtime routines. Delayed sleep phase was managed using bedtime fading whereby the child's bedtime is temporarily set later and gradually brought forward, while continuing to wake the child at a preset time in the morning. Anxiety related insomnia was managed by visual imagery and relaxation techniques. Parents were asked to complete a sleep diary between the first and second consultation. The second consultation and follow-up telephone call were used to review the sleep diary, reinforce suggested strategies, and troubleshoot any problems.

Families were provided with information sheets designed for the study, dealing with normal sleep, common sleep problems, and strategies for managing specific problems (see supplementary information). The clinicians completed a standardised consultation form, recording the duration of the consultation and key components of the programme (history, diagnoses, management) to maximise programme fidelity. ${ }^{11} \mathrm{HH}$ and ES met with the clinicians fortnightly to consult on clinical issues.

\section{Measures}

The box summarises the baseline and outcome measures. We administered parent and teacher surveys at baseline and at three and six months. At six months, trained research staff blinded to whether the child had received the intervention administered a face to face assessment of working memory. A subset of children whose parents were willing to do so provided actigraphy data (Actiwatch 2; Philips Respironics) at baseline and follow-up to objectively measure duration of night time sleep, wake after sleep onset, and sleep efficiency (ratio of time asleep to time spent in bed). At each of these times the actigraphy device was worn for one week.

\section{Sample size}

Our primary outcome was the severity of ADHD symptoms, as reported by parents and teachers, at three months after randomisation. ${ }^{12}$ In a departure from protocol and to align with the move towards limiting the number of primary outcome measures, we did not include symptom severity at the 12 month time point as a primary outcome. To detect a 0.4 standard deviation mean difference in change in symptom severity between the intervention and usual care group, we required 99 children in each arm at the three month follow-up (198 total children) to have $80 \%$ power at the two sided $5 \%$ level of significance to detect this effect. A 0.4 standard deviation mean difference corresponded with approximately 3.86 points on the ADHD rating scale IV in our observed data. Allowing for a $20 \%$ loss to follow-up, we required 118 children in each arm. We decided to base our sample size on being able to detect a 0.4 standard deviation difference between the intervention and control group on ADHD symptoms, which would also provide enough power to detect a difference in sleep problems. This is because it is uncertain whether a difference of 0.3 standard deviations in ADHD symptoms is clinically meaningful. In our pilot study (with small numbers) ${ }^{11}$ we were able to detect 0.4-0.5 standard deviation differences on other outcomes of interest, such as the children's quality of life and daily functioning and parental mental health.

\section{Statistical methods}

Analysis was conducted on an intention to treat basis. For parent reported outcomes, we calculated the changes in each outcome between baseline and three months and between baseline and six months. We estimated the mean differences in the change in the outcomes between the intervention and control arms and $95 \%$ confidence intervals using linear regression adjusted for confounders identified a priori. The confounders were the child's age, sex, medication use (yes or no), and total number of mental health comorbidities identified on the anxiety disorders interview schedule for children IV; age and education level of primary caregiver (completed high school: yes or no); and family socioeconomic status, measured according to postal code of residence using the index of relative socioeconomic disadvantage. ${ }^{19}$ To calculate effect sizes, we standardised the changes in each outcome to a mean of 0 and a standard deviation of 1 , and repeated regression analyses. Effect sizes with standard deviations of 0.20 or less are considered as small, 0.50 or less as moderate, and around 0.80 as large. ${ }^{20}$

For teacher reported outcome we compared the outcome between the intervention and control arms, adjusting for baseline scores and confounders rather than considering change in scores, as originally specified in the protocol. We used this alternative approach because many of the children had changed teachers between the three and six month surveys and the baseline survey ( 74 children at three months, 121 children at six months) and thus the correlation between teachers' measures was lower than expected and the analysis of change scores was a less efficient approach. $^{21}$

Using logistic regression we compared the proportions of children with moderate-severe versus no or mild sleep problems between the two arms; we estimated odds ratios and 95\% confidence intervals adjusted for potential confounders.

To detect whether any improvement in the severity of ADHD symptoms was associated with improvement in sleep, we conducted a post hoc analysis of mediation. We examined whether the improvement in parent reported total symptom scores for the intervention group at three and six months, compared with the control group, was mediated by improved sleep (children's sleep habits questionnaire total score) using 


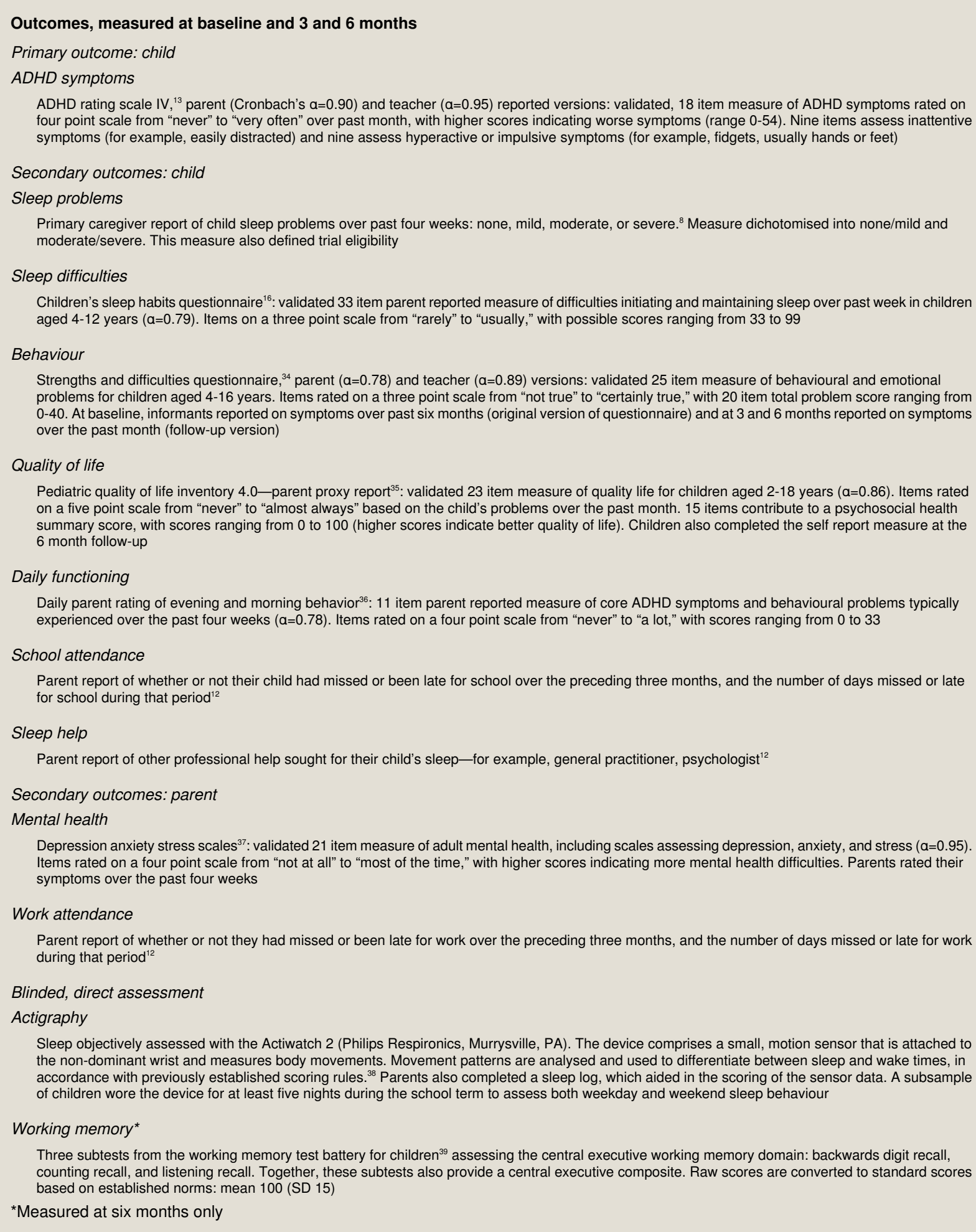

causal mediation models. ${ }^{22}$ All mediation models were adjusted for confounding variables (as previously).

Using a non-parametric test for trend we compared the number of days the child missed or was late for school and the parent for work, between the two arms, coding responses as $0,1,2,3$, 4 , or 5 or more days missed or late for school or work in the preceding three months. We selected this approach given the skewed distribution of these data and the high proportion of 0 responses.

We examined the frequency and patterns of missing data and performed analyses comparing the results based on families with complete data with analyses where missing data were imputed. ${ }^{23}$ A chained equation multiple imputation model was implemented including all variables that were to be used in the analysis model. In this model we imputed 40 completed datasets including all children initially randomised. ${ }^{24}$ Given our sample size and the complexity of the data we were able to produce analytical results for our primary and key secondary outcomes. In our tables we report both non-imputed and imputed results (key findings) and focus on the latter in our results. We report unimputed results for child and parent school or work attendance, working memory, and actigraphy data, given that this was a subsample analysis. All analyses were conducted using Stata version 12.0. ${ }^{25}$ 


\section{Results}

\section{Sample characteristics}

Between August 2010 and June 2012, 50 paediatricians from 21 general practices identified 1349 potentially eligible families, of whom 336 were confirmed as being eligible and 244 consented to participate (figure $\Downarrow$ ). Families who participated were comparable to non-participating families for the child's sex and age and mean neighbourhood socioeconomic disadvantage. Table $1 \Downarrow$ shows the baseline characteristics of the sample. Most of the children were boys, were taking stimulant medications, and had an internalising or externalising comorbidity. Most of the primary caregivers were mothers. Changes to medication schedules were similar across the intervention and control groups, with 14 intervention and 19 control families reporting changes at three months, and 22 and 27 , respectively, reporting changes at six months.

\section{Primary outcome: parent and teacher reported ADHD symptoms}

Complete data were provided by 79 intervention and 85 control families at three months, and by 99 intervention and 97 control families at six months. Families with complete data did not differ significantly from those with incomplete data for ADHD symptom severity, child's age and sex, family socioeconomic disadvantage, or primary caregiver education at either time point. The results reported here are based on our imputed dataset.

The adjusted mean difference in change in severity of ADHD symptoms between the two groups was significant albeit modest (adjusted mean difference $-2.9,95 \%$ confidence interval -5.5 to $-0.3, \mathrm{P}=0.03$, effect size -0.3 ; table $2 \Downarrow$ ), with the greatest reduction for inattentive symptoms (adjusted mean difference $-1.9,-3.4$ to $-0.4, \mathrm{P}=0.01$, effect size -0.4 ). These benefits were maintained and slightly strengthened at six months.

Teacher reported mean ADHD severity scores were higher at baseline in the usual care group versus intervention group. Therefore, in a post hoc analysis, we analysed parent reported outcomes additionally controlling for teacher reported baseline total ADHD scores and total strengths and difficulties questionnaire scores. Estimated effects of the intervention based on parent report did not change substantially.

Analysis of teacher reported scores included 71 intervention and 77 usual care children at three months, and 83 intervention and 87 usual care children at six months, again comparable to those originally randomised. Teacher reported total ADHD scores were similar between the two groups at three and six months.

\section{Key secondary outcomes}

Compared with control children, intervention children had fewer moderate or severe sleep problems in imputed analyses at three months $(56 \%$ v $30 \%$, adjusted odds ratio $0.30,95 \%$ confidence interval 0.16 to $0.59 ; \mathrm{P}<0.001)$ and six months $(46 \%$ v $34 \%$, $0.58,0.32$ to $1.0 ; \mathrm{P}=0.07)$. At three months this equates to a reduction in absolute risk of $25.7 \%$ (95\% confidence interval $14.1 \%$ to $37.3 \%$ ) and an estimated number needed to treat of 3.9 (95\% confidence interval 2.7 to 7.1 ). At six months the estimated adjusted reduction in absolute risk was $12.8 \%(0.6 \%$ to $25.0 \%$ ) and number needed to treat was 7.8 (4.0 to 172.5).

Similarly, intervention children experienced greater improvements in almost all other outcomes compared with control children (table $3 \Downarrow$ ). At three and six months, intervention children had a greater reduction in sleep difficulties on the children's sleep habits questionnaire (effect size -0.8 and -0.6 , respectively), reduction in behavioural difficulties (effect size -0.5 and -0.4 ), improvement in quality of life psychosocial score (effect size 0.7 and 0.4 ), and reduction in difficulties in daily functioning (effect size -0.6 and -0.4 ). Similarly, teachers reported greater reductions in behaviour difficulties in intervention children than in control children at both three and six months (effect size -0.3). There were no evident differences in parent reported total depression, anxiety, and stress symptoms at three or six months. Although intervention children were less likely than control children to have help sought for their sleep from a health professional, including a general practitioner, paediatrician, or psychologist (17 and 24 at three months and 25 and 43 at six months), these differences were not significant.

\section{Other findings}

At three months, intervention parents reported fewer days late for work as a result of their child's behaviour than control parents $(\mathrm{P}=0.02$, non-parametric test for trend $)$ and fewer missed days at work $(\mathrm{P}=0.03)$; these differences were not maintained at six months. The number of days that children missed school did not differ between groups at three or six months. Intervention children were less likely to be late for school at the six month follow-up $(\mathrm{P}=0.02)$ but not at the three month follow-up. At the six month direct assessment, backwards digit recall, assessed by blinded raters, was higher in the intervention children than control children (adjusted mean difference 5.2, 95\% confidence interval 0.03 to 10.4 , effect size $0.3 ; \mathrm{P}=0.05$ ). Performance on listening and counting recall did not differ between the two arms. There was no statistically significant difference in child reported quality of life between the intervention and control groups.

\section{Mediation analysis}

For the mediation analyses, we restricted the sample to participants with complete data across several variables: severity of ADHD symptoms (ADHD rating scale IV—-total score), severity of sleep problems (children's sleep habits questionnaire - total score), and all a priori confounding variables ( $\mathrm{n}=153$ at three months, $\mathrm{n}=192$ at six months). At three months, the total mean difference in change in total ADHD symptom scores between the intervention and control groups was -3.1 (95\% confidence interval -5.6 to $-0.7 ; \mathrm{P}=0.14)$, of which -1.56 ( -2.9 to $-0.2 ; \mathrm{P}=0.03$ ) was mediated through improved children's sleep habits questionnaire total score, and $-1.6(-4.3$ to $1.1 ; \mathrm{P}=0.25)$ was explained directly by the intervention (or through other pathways not examined). At six months, the total mean difference in change in total ADHD symptom scores between groups was -3.5 ( -5.8 to -1.2 ; $\mathrm{P}=0.003)$, of which $-1.2(-2.1$ to $-0.3 ; \mathrm{P}=0.01)$ was mediated through improved children's sleep habits questionnaire total score, and -2.3 ( -4.7 to $-0.003 ; \mathrm{P}=0.05)$ was explained directly or through other pathways. Thus at three and six months, 50\% and $33 \%$ of the effect of the intervention on severity of ADHD symptoms was mediated through improved sleep in the children.

\section{Actigraphy}

We collected actigraphy data from a subgroup of consenting participants ( $\mathrm{n}=25$ intervention, $\mathrm{n}=29$ control) at baseline and three months and at baseline and six months ( $\mathrm{n}=17$ intervention, $\mathrm{n}=20$ control). Children with complete actigraphy data had less severe symptoms of ADHD, were younger, and were from more socially advantaged neighbourhoods than children with incomplete actigraphy data. There were no statistically significant differences between groups in sex of the children. 
There was some evidence that at three and six months sleep duration per night had increased in the intervention group (mean difference 10.9 minutes, $95 \%$ confidence interval -19.0 to 40.8 , effect size 0.2 and 9.9 minutes, -16.3 to 36.1 , effect size 0.3 ; table $4 \Downarrow$ ). Given the small sample size, we did not conduct adjusted analyses for these sleep variables.

\section{Programme fidelity}

Of the 122 children randomised to receive intervention, 114 received intervention and clinicians completed a standardised consultation form for 113 of these children. Overall, 113 families $(100 \%)$ received the first consultation (mean duration 60 minutes, range 15-86 minutes), $106(92 \%)$ received the second consultation (30 minutes, 5-65 minutes), and 72 (64\%) received the telephone call (13 minutes, 3-30 minutes). In all forms the sections for diagnosis and management were completed, with an average of 2.2 diagnoses and 2.9 management strategies for each child.

From baseline to six months, parents of intervention children reported visiting their child's paediatrician 0.3 times (SD 0.7, range: 0-3) for their child's sleep problem, whereas parents of control children reported visiting their child's paediatrician 0.6 (SD 1.4, range 0-7) times.

\section{Discussion}

In this randomised controlled trial, a behavioural sleep intervention in children with attention deficit hyperactivity disorder (ADHD) and sleep problems was associated with several substantial and sustained benefits for both the children and their families. The families reported greater improvements in their children's ADHD symptoms, sleep, behaviour, health related quality of life, and daily functioning, and teachers reported improved behaviour. The parents also reported increased work attendance, and at six months the children also tended to have improved working memory and fewer days late for school. Data from actigraphy suggested an improved sleep duration of around 70 minutes a week in the intervention group. However, similar to other groups attempting to use the actigraphy devices (Actiwatch 2; Philips Respironics) in children with developmental problems, ${ }^{26}$ we encountered several practical issues (children refusing to wear, destroying, or losing the device), so these results must be interpreted with caution.

\section{Strengths and limitations of this study}

Our study has several strengths. Firstly, we included a large sample of children drawn from multiple practices and we included children with a wide range of comorbidites (except intellectual disability, IQ <70) so our results are likely to generalise to most children with ADHD and sleep problems seen in community clinical settings. The proportions of comorbidites in our sample were generally consistent with previous studies, ${ }^{32} 33$ but proportions of internalising difficulties were somewhat higher, which might reflect the inclusion of children with comorbid autism spectrum disorders in our sample. Secondly, our study was adequately powered and used validated measures where possible. Despite our large sample size, the confidence intervals around the number needed to treat for sleep problems at six months was noticeably wide, reflecting that the risk difference at the lower end of the confidence interval approaches 0 (that is, no treatment effect). Thirdly, we designed our intervention to be readily replicable in primary or secondary care clinical practice.
Our study had some limitations. Parents were aware of whether their child had received the intervention, which may have led to response bias whereby parents overstated improvements in their child in response to the intervention. This could lead to an overestimate of the effect of the intervention, particularly in the period soon after the consultations and telephone call had been received. However, the sustained effects up to six months suggest that the treatment effect observed is robust rather than an effect of parent report. Our response rate at three months was relatively low, although families who provided data did not differ from those who did not on key outcomes, and multiple imputation did not change our findings. It is, however, possible that participation was biased towards more highly motivated families. We included a broad range of secondary outcome measures, which may have increased the likelihood of chance findings.

\section{Comparison with other studies}

In our study, the relative reduction in ADHD symptoms between the two arms was of the order of effect sizes from 0.3 to 0.4 , which is comparable to that observed in more intensive unblinded behavioural interventions. ${ }^{6}$ Although the effect size of 0.3 at three months is of uncertain clinical importance, it strengthened at six months after randomisation (0.4) and we also obtained benefits in teacher reports of children's behaviour at three and six months. Stimulant medications have been shown to be the most effective intervention for reducing the core symptoms of ADHD (inattention, hyperactivity, and impulsivity), ${ }^{27}$ with effect sizes in the order of $0.8 .{ }^{28}{ }^{29}$ Importantly, the effects of our intervention were evident for a community based sample of children with ADHD, most of whom were already taking a stimulant medication. It should be noted that despite taking medication for ADHD, participants were still quite symptomatic, as evidenced by scores greater than the 90th centile on the parent report version of the ADHD rating scale IV,$^{13}$ and all continued to meet the criteria of the Diagnostic and Statistical Manual of Mental Disorders, fourth revision, for ADHD.

Previous studies have aimed to improve sleep and the severity of ADHD symptoms through the use of melatonin. Two double blind placebo controlled trials found that melatonin reduced the latency of sleep onset (that is, the time taken to fall asleep) but had no effect on ADHD symptoms, behaviour, or quality of life. ${ }^{30}$ Our intervention found additional benefits to that of a reduction in time taken to fall asleep seen with melatonin. There are several possible explanations for this. Firstly, whereas melatonin only helps with sleep onset, our intervention targeted sleep problems that occur overnight as well as at sleep onset, and as such may have improved the child's quality or quantity of sleep, or both to a greater extent. Secondly, teaching parents how to set limits around bedtime and how to manage a child's anxiety related initial insomnia may improve parenting more generally. Thus parents may be better equipped to manage oppositional behaviour or anxiety, with subsequent flow on benefits for the child's behaviour, daily functioning, and quality of life. This may also explain why intervention benefits were seen mostly at home rather than at school. It may also explain why improvements in ADHD symptoms were only partially mediated by improvements in sleep (that is, other factors, such as parenting style) may have played a part.

\section{Conclusions and implications}

In summary, a brief behavioural treatment for sleep problems in children with ADHD can lead to substantial and sustained benefits for children and their families. These benefits occur 
over and above the effects of stimulant medications. Effects are comparable to those seen with intensive behavioural interventions targeting ADHD symptoms, more wide reaching than those reported in studies of melatonin, and importantly seem to be sustained over six months. These findings suggest that clinical management of sleep symptoms can reap benefits for the considerable number of children with ADHD who have moderate-severe behavioural sleep problems. Follow-up of this sample will allow us to determine long term benefits and healthcare costs or savings. Future research will take the next step in the translation pathway to determine whether these benefits can be replicated when the sleep intervention is implemented by community based clinicians in a rigorous effectiveness trial.

We thank the families, paediatricians, and teachers for taking part in the study and the following project staff for their contribution in data collection or delivery of the intervention: Joshua Bekker, Dorothy Bruck, Bronwyn Campbell, Kathleen Chan, Grace Gordon, Alisha Gulenc, Cassandra Litleton, Kate Lycett, Rebecca Mitchell, Rebecca Palmieri, Jonathan Reyes, Jane Sheehan, Holly Wilson, and Nardia Zendarski.

Contributors: HH, ES, DE, FM, and FO made substantial contributions to the conception and design of the trial. SK and BG acquired the data. ES analysed the data under the supervision of FM. HH, ES, and FM interpreted the data. $\mathrm{HH}, \mathrm{ES}$, and FM drafted the manuscript. DE, SK, $B G$, and FO critically reviewed the article for important intellectual content. All authors gave final approval of the version to be published. All authors had full access to all the data (including statistical reports and tables) in the study and can take responsibility for the integrity of the data and the accuracy of the data analysis. $\mathrm{HH}$ is the guarantor.

Funding: The study was supported by a project grant (No 607362) from the Australian National Health and Medical Research Council (NHMRC). ES's and FM's positions are funded by NHMRC early career fellowships in population health (No 1037159 and No 1037449). HH's position is funded by an NHMRC career development award (No 607351). HH, $\mathrm{ES}$, and FM were also supported by an NHMRC population health capacity building grant (No 436914) during the conduct of the trial. Murdoch Childrens Research Institute is supported by the Victorian Government's operational infrastructure support programme. The NHMRC had no role in the study design, the collection, analysis, and interpretation of the data, the drafting of the manuscript, or the decision to submit this paper for publication. All researchers worked independently from the funder.

Competing interests: All authors have completed the ICMJE uniform disclosure form at www.icmje.org/coi_disclosure.pdf and declare: no support from any organisation for the submitted work; no financial relationships with any organisations that might have an interest in the submitted work in the previous three years; no other relationships or activities that could appear to have influenced the submitted work.

Ethical approval: This study was approved by human research ethics committees of The Royal Children's Hospital (No 30033) and the Victorian Department of Education and Early Childhood Development (No 2010_000573).

Data sharing: Patient level data and full dataset are available from the corresponding author at harriet.hiscock@rch.org.au. Consent was not obtained but the presented data are anonymised and risk of identification is low.

Transparency: The lead author $(\mathrm{HH})$ affirms that the manuscript is an honest, accurate, and transparent account of the study being reported; that no important aspects of the study have been omitted; and that any discrepancies from the study as planned (and, if relevant, registered) have been explained.
1 Polanczyk G, de Lima MS, Horta BL, Biederman J, Rohde LA. The worldwide prevalence of ADHD: a systematic review and metaregression analysis. Am J Psychiatry 2007:164:942-8.

2 Barbaresi WJ, Katusic SK, Colligan RC, Weaver AL, Jacobsen SJ. Long-term school outcomes for children with attention-deficit/hyperactivity disorder: a population-based perspective. J Dev Behav Pediatr 2007;28:265-87.

3 Barkley RA, Fischer M, Smallish L, Fletcher KE. Young adult outcome of hyperactive children: adaptive functioning in major life activities. J Am Acad Child Adolesc Psychiatry 2006:45:192-202.

4 Yoshimasu K, Barbaresi WJ, Colligan RC, Voigt RG, Killian JM, Weaver AL, et al. Childhood ADHD is strongly associated with a broad range of psychiatric disorders during adolescence: a population-based birth cohort study. J Child Psychol Psychiatry 2012;53:1036-43.

5 Doshi JA, Hodgkins P, Kahle J, Sikirica V, Cangelosi MJ, Setyawan J, et al. Economic impact of childhood and adult attention-deficit/hyperactivity disorder in the United States. J Am Acad Child Adolesc Psychiatry 2012;51:990-1002.

6 Sonuga-Barke EJ, Brandeis D, Cortese S, Daley D, Ferrin M, Holtmann M, et al. Nonpharmacological interventions for ADHD: systematic review and meta-analyses of randomized controlled trials of dietary and psychological treatments. Am J Psychiatry 2013;170:275-89.

7 Quach J, Hiscock H, Ukoumunne OC, Wake M. A brief sleep intervention improves outcomes in the school entry year: a randomized controlled trial. Pediatrics 2011;128:692-701

8 Sung V, Hiscock H, Sciberras E, Efron D. Sleep problems in children with attention-deficit/hyperactivity disorder-prevalence and the effect on the child and family. Arch Pediatr Adolesc Med 2008;162:336-42.

9 Yoon SY, Jain U, Shapiro C. Sleep in attention-deficit/hyperactivity disorder in children and adults: past, present, and future. Sleep Med Rev 2012;16:371-88.

10 Cortese S, Brown TE, Corkum P, Gruber R, O'Brien LM, Stein M, et al. Assessment and management of sleep problems in youths with attention-deficit/hyperactivity disorder. $J$ Am Acad Child Adolesc Psychiatry 2013;52:784-96.

11 Sciberras E, Fulton M, Efron D, Oberklaid F, Hiscock H. Managing sleep problems in school aged children with ADHD: a pilot randomised controlled trial. Sleep Med 2011;12:932-5.

12 Sciberras E, Efron D, Gerner B, Davey M, Mensah F, Oberklaid F, et al. Study protocol: the sleeping sound with attention-deficit/hyperactivity disorder project. BMC Pediatr 2010;10:101.

13 DuPaul GJ, Power TJ, Anastopoulos AD, Reid R. ADHD rating scale IV: checklists, norms, and clinical interpretation. Guilford Publications, 1998

14 American Psychiatric Association. Diagnostic and statistical manual of mental disorders IV, 4th revision. APA, 2000

15 American Academy of Sleep Medicine. The international classification of sleep disorders, revised: diagnostic and coding manual. AASM, 2001.

16 Owens J, Spirito A, McGuinn M. The Children's Sleep Habits Questionnaire (CSHQ): psychometric properties of a survey instrument for school aged children. Sleep 2000:23:1043-51.

17 Lyneham HJ, Rapee RM. Agreement between telephone and in-person delivery of a structured interview for anxiety disorders in children. J Am Acad Child Adolesc Psychiatry 2005;44:274-82.

18 Mindell JA, Owen J. A clinical guide to pediatric sleep: diagnosis and management of sleep problems in children and adolescents. 2nd ed. Lippincott Williams \& Wilkins 2010.

19 Australian Bureau of Statistics. Census of Population and Housing: Socio-Economic Indexes for Areas (SEIFA), Australia - data only Canberra: ABS, 2013. www.abs.gov.au/ AUSSTATS/abs@.nsf/DetailsPage/2033.0.55.0012011?OpenDocument.

20 Cohen J. A power primer. Psychol Bull 1992;112:155-9.

21 Vickers AJ, Altman DG. Statistics notes: analysing controlled trials with baseline and follow up measurements. BMJ 2001:323:1123.

22 Imai K, Keele L, Tingley D. A general approach to causal mediation analysis. Psychol Methods 2010;15:309-34

23 Sterne J, White I, Carlin J, Spratt M, Royston P, Kenward M, et al. Multiple imputation for missing data in epidemiological and clinical research: potential and pitfalls. $B M J$ 2009;338:b2393.

24 Spratt M, Carpenter J, Sterne JAC, Carlin JB, Heron J, Henderson J, et al. Strategies for multiple imputation in longitudinal studies. Am J Epidemiol 2010;172:478-87.

25 StataCorp. Stata statistical software: release 12. StataCorp LP, 2011.

26 Gringras P, Gamble C, Jones AP, Wiggs L, Williamson PR, Sutcliffe A, et al. Melatonin for sleep problems in children with neurodevelopmental disorders: randomised double masked placebo controlled trial. BMJ 2010;345:e6664.

27 The MTA Cooperative group. A 14-month randomized clinical trial of treatment strategies for attention-deficit/hyperactivity disorder. Arch Gen Psychiatry 1999;56:1073-86.

28 Brown RT, Amler RW, Freeman WS, Perrin JM, Stein MT, Feldman HM, et al. Treatment of attention-deficit/hyperactivity disorder: overview of the evidence. Pediatrics 1998;115:e749-57.

29 Schachter HM, Pham B, King J, Langford S, Moher D. How efficacious and safe is short-acting methylphenidate for the treatment of attention-deficit disorder in children and adolescents? A meta-analysis. Can Med Assoc J 2001:165:1475-88.

30 Van der Heijden KB, Smits MG, Van Someren EJ, Ridderinkhof KR, Gunning WB. Effect of melatonin on sleep, behaviour and cognition in ADHD and chronic sleep onset insomnia. J Am Acad Child Adolesc Psychiatry 2007;46:233-41.

31 Weiss MD, Wasdell MB, Bomben MM, Rea KJ, Freeman RD. Sleep hygiene and melatonin treatment for children and adolescents with ADHD and initial insomnia. J Am Acad Child Adolesc Psychiatry 2006:45:512-9.

32 Gillberg C, Gillberg IC, Rasmussen P, Kadesjö B, Söderström H, Råstam M, et al. Co-existing disorders in ADHD-implications for diagnosis and intervention. Eur Child Adolesc Psychiatry 2004;13(Supp 1):i80-i92.

33 Reiersen AM, Constantino JN, Volk HE, Todd RD. Autistic traits in a population-based ADHD twin sample. J Child Psychol Psychiatry 2007;48:464-72.

34 Goodman R. Psychometric properties of the Strengths and Difficulties Questionnaire. J Am Acad Child Adolesc Psychiatry 2001;40:1337-45.

35 Varni J, Burwinkle TM, Seid M, Skarr D. The PedsQL 4.0 as a pediatric population health measure: feasibility, reliability, and validity. Ambul Pediatr 2003;3:329-41.

36 Kelsey DK, Sumner CR, Casat CD. Once-daily atomoxetine treatment for children with attention-deficit/hyperactivity disorder, including an assessment of evening and morning behaviour: a double-blind placebo controlled trial. Pediatrics 2004;114:e1-e8. 


\section{What is already known on this topic}

Behavioural sleep problems are common in children with attention deficit hyperactivity disorder (ADHD) and are associated with poor child and family outcomes

No randomised controlled trials have assessed the effect of treating behavioural sleep problems on child and family functioning in children with ADHD

\section{What this study adds}

A brief, tailored behavioural sleep intervention for children with ADHD and sleep problems improves not only sleep but the severity of ADHD symptoms, behaviour, daily functioning, quality of life, and working memory, six months after randomisation

The brevity of the intervention is such that it may be suitable for use in primary care

37 Lovibond PH, Lovibond SH. The structure of negative emotional states: comparison of the Depression Anxiety Stress Scales (DASS) with the Beck Depression and Anxiety Inventories. Behav Res Ther 1995;33:335-43.

38 Meltzer LJ, Westin AM. A comparison of actigraphy scoring rules used in pediatric research. Sleep Med 2011;12:793-6.

39 Pickering S, Gathercole S. Working Memory Test Battery for Children (WMTB-C). Pearson Education, 2001.

Accepted: 10 December 2014

\section{Cite this as: BMJ 2015;350:h68}

This is an Open Access article distributed in accordance with the Creative Commons Attribution Non Commercial (CC BY-NC 4.0) license, which permits others to distribute, remix, adapt, build upon this work non-commercially, and license their derivative works on different terms, provided the original work is properly cited and the use is non-commercial. See: http://creativecommons.org/licenses/by-nc/4.0/. 


\section{Tables}

\section{Table 1| Baseline sample characteristics of participants. Values are numbers (percentages) unless stated otherwise}

\begin{tabular}{|c|c|c|}
\hline Characteristics & Intervention group $(n=122)^{\star}$ & Control group $(n=122)^{*}$ \\
\hline \multicolumn{3}{|l|}{ Children } \\
\hline Boys & $103(84)$ & $105(86)$ \\
\hline Mean (SD) age (years) & $10.3(1.8)$ & $9.9(2.1)$ \\
\hline Medication use: & $105(88)$ & $106(88)$ \\
\hline Methylphenidate & $93(76)$ & $91(74)$ \\
\hline Atomoxetine & $7(6)$ & $7(6)$ \\
\hline Clonidine & $11(9)$ & $4(3)$ \\
\hline \multicolumn{3}{|l|}{ Parent reported comorbidities: } \\
\hline Learning difficulties & $42(34)$ & $42(34)$ \\
\hline Autism spectrum or Asperger disorder & $28(23)$ & $33(27)$ \\
\hline \multicolumn{3}{|l|}{ Anxiety disorders interview schedule for children IV: } \\
\hline Internalising comorbidity $\dagger$ & $73(64)$ & $67(60)$ \\
\hline Externalising comorbidity $\ddagger$ & $76(68)$ & $77(69)$ \\
\hline \multicolumn{3}{|l|}{ Primary caregiver: } \\
\hline Mother & $114(95)$ & $116(97)$ \\
\hline Mean (SD) age (years) & $39.4(5.9)$ & $40.0(6.7)$ \\
\hline Completed high school & $62(51)$ & $57(47)$ \\
\hline College or postgraduate degree & $26(22)$ & $26(23)$ \\
\hline Employed & $74(61)$ & $64(52)$ \\
\hline \multicolumn{3}{|l|}{ Family } \\
\hline Mean (SD) index of relative socioeconomic disadvantage & $1007.3(69.9)$ & $999.2(60.6)$ \\
\hline \multicolumn{3}{|l|}{ Income per annum $(\$ A)$ : } \\
\hline$<30000$ & $28(24)$ & $34(28)$ \\
\hline $30001-60000$ & $39(33)$ & $33(27)$ \\
\hline $60001-90000$ & $26(22)$ & $25(21)$ \\
\hline$>90000$ & $26(22)$ & $29(24)$ \\
\hline
\end{tabular}

*Parent baseline data were available for all children and teacher data for 205 children (84\%: 103 intervention, 102 usual care). Numbers range from $224-244$. †Children meeting criteria for two or more anxiety disorders (separation anxiety disorder, social phobia, specific phobia, generalised anxiety disorder, panic disorder, obsessive compulsive disorder, post-traumatic stress disorder) or one mood disorder (major depressive episode, or dysthymia) on the anxiety interview schedule for children IV.

‡Children meeting criteria for oppositional defiant disorder or conduct disorder on the anxiety interview schedule for children IV. 
Table 2| Comparison of severity of symptoms of attention deficit hyperactivity disorder (ADHD) between intervention and control children

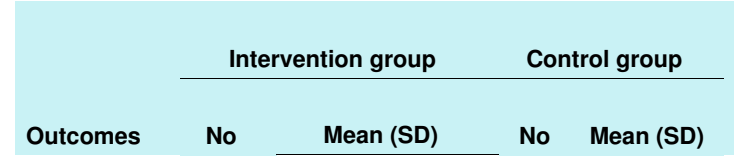

\begin{tabular}{|c|c|c|}
\hline \multicolumn{3}{|c|}{$\begin{array}{l}\text { Adjusted difference } \\
\text { (intervention-control) }\end{array}$} \\
\hline $\begin{array}{l}\text { Mean }(95 \% \\
\text { Cl) }\end{array}$ & $\begin{array}{l}\text { Effect } \\
\text { size }\end{array}$ & $P$ value \\
\hline
\end{tabular}

Adjusted difference with multiple imputation (intervention-control)

Mean $(95 \% \quad$ Effect

Outcomes No $\quad$ Mean (SD)

Total ADHD

symptoms:

\begin{tabular}{|c|c|c|c|c|c|c|c|c|c|c|}
\hline Baseline & 120 & $35.6(9.4)$ & 122 & $37.1(9.9)$ & - & - & - & - & - & - \\
\hline 3 months & 85 & $29.7(10.7)$ & 88 & $33.2(9.6)$ & $\begin{array}{c}-3.7(-6.1 \text { to } \\
-1.2)\end{array}$ & -0.5 & 0.004 & $\begin{array}{c}-2.9(-5.5 \text { to } \\
-0.3)\end{array}$ & -0.3 & 0.03 \\
\hline 6 months & 105 & $28.4(10.8)$ & 98 & $33.8(9.5)$ & $\begin{array}{c}-3.9(-6.3 \text { to } \\
-1.5)\end{array}$ & -0.5 & 0.001 & $\begin{array}{c}-3.7(-6.1 \text { to } \\
-1.2)\end{array}$ & -0.4 & 0.004 \\
\hline \multicolumn{11}{|l|}{ Inattentive: } \\
\hline Baseline & 120 & $18.8(5.2)$ & 122 & $19.6(5.3)$ & - & - & - & - & - & - \\
\hline 3 months & 85 & $15.8(5.5)$ & 88 & $17.8(5.2)$ & $\begin{array}{c}-2.4(-3.8 \text { to } \\
-1.0)\end{array}$ & -0.5 & 0.001 & $\begin{array}{c}-1.9(-3.4 \text { to } \\
-0.4)\end{array}$ & -0.4 & 0.01 \\
\hline 6 months & 105 & $15.1(6.0)$ & 98 & $18.2(4.8)$ & $\begin{array}{c}-2.4(-3.7 \text { to } \\
-1.0)\end{array}$ & -0.5 & 0.001 & $\begin{array}{c}-2.3(-3.6 \text { to } \\
-0.9)\end{array}$ & -0.5 & 0.001 \\
\hline
\end{tabular}

Hyperactive or

impulsive:

\begin{tabular}{|c|c|c|c|c|c|c|c|c|c|c|}
\hline Baseline & 121 & $16.8(5.3)$ & 122 & $17.6(5.8)$ & - & - & - & - & - & - \\
\hline 3 months & 85 & $15.4(5.7)$ & 88 & $13.9(5.9)$ & $\begin{array}{c}-1.3(-2.5 \\
\text { to.0) }\end{array}$ & -0.3 & 0.05 & $\begin{array}{c}-1.0(-2.3 \text { to } \\
0.3)\end{array}$ & -0.2 & 0.13 \\
\hline 6 months & 106 & $13.3(6.0)$ & 98 & $15.6(5.8)$ & $\begin{array}{c}-1.5(-2.8 \text { to } \\
-0.2)\end{array}$ & -0.3 & 0.02 & $\begin{array}{c}-1.4(-2.7 \text { to } \\
-0.1)\end{array}$ & -0.3 & 0.04 \\
\hline
\end{tabular}

\section{ADHD rating scale IV-teacher report}

Total ADHD

symptoms:

\begin{tabular}{|c|c|c|c|c|c|c|c|c|c|c|}
\hline Baseline & 103 & $24.2(13.2)$ & 102 & $28.2(13.0)$ & - & - & - & - & - & - \\
\hline 3 months & 83 & $22.5(13.0)$ & 87 & $27.8(12.5)$ & $\begin{array}{c}-2.4(-5.3 \text { to } \\
0.4)\end{array}$ & -0.2 & 0.09 & $\begin{array}{c}-2.4(-5.0 \text { to } \\
0.3)\end{array}$ & -0.2 & 0.08 \\
\hline 6 months & 98 & $20.6(11.6)$ & 98 & $25.1(12.6)$ & $\begin{array}{c}-2.4(-5.8 \text { to } \\
1.0)\end{array}$ & -0.2 & 0.17 & $\begin{array}{c}-1.7(-4.9 \text { to } \\
1.6)\end{array}$ & -0.1 & 0.31 \\
\hline \multicolumn{11}{|l|}{ Inattentive: } \\
\hline Baseline & 103 & $13.7(7.7)$ & 102 & $15.8(7.0)$ & - & - & - & - & - & - \\
\hline 3 months & 83 & $13.1(7.1)$ & 87 & $15.4(6.4)$ & $\begin{array}{c}-0.7(-2.3 \text { to } \\
0.8)\end{array}$ & -0.1 & 0.35 & $\begin{array}{c}-0.6(-2.1 \text { to } \\
0.8)\end{array}$ & -0.1 & 0.36 \\
\hline 6 months & 98 & $14.1(6.9)$ & 98 & $12.3(6.9)$ & $\begin{array}{c}-0.9(-2.9 \text { to } \\
1.0)\end{array}$ & -0.1 & 0.35 & $\begin{array}{c}-0.5(-2.4 \text { to } \\
1.3)\end{array}$ & -0.1 & 0.59 \\
\hline
\end{tabular}

Hyperactive or

impulsive:

\begin{tabular}{|c|c|c|c|c|c|c|c|c|c|c|}
\hline Baseline & 103 & $10.4(6.8)$ & 102 & $12.4(7.2)$ & - & - & - & - & - & - \\
\hline 3 months & 83 & $9.4(7.1)$ & 87 & $12.3(7.1)$ & $\begin{array}{c}-1.8(-3.4 \text { to } \\
-0.2)\end{array}$ & -0.2 & 0.03 & $\begin{array}{c}-1.8(-3.3 \text { to } \\
-0.2)\end{array}$ & -0.3 & 0.02 \\
\hline 6 months & 98 & $8.4(6.2)$ & 98 & $10.9(7.1)$ & $\begin{array}{c}-1.4(-3.3 \text { to } \\
0.4)\end{array}$ & -0.2 & 0.12 & $\begin{array}{c}-1.1(-2.9 \text { to } \\
0.6)\end{array}$ & -0.2 & 0.19 \\
\hline
\end{tabular}

Differences (change in symptom severity from baseline for parent report, and difference in severity for teacher report) adjusted for children's age, sex, medication use (yes or no), total number of mental health comorbidities, parental age, parental completion of high school (yes or no), socioeconomic status (index of relative socioeconomic disadvantage).

For parent reported outcomes mean intervention versus control differences in change from baseline to outcome at three and six months adjusted for all confounding variables; for teacher reported outcomes, mean intervention versus control differences in outcome at three and six months, adjusted for baseline scores and all confounding variables. 
Table 3| Comparison of secondary outcomes between intervention and control children

\begin{tabular}{|c|c|c|c|c|c|c|c|c|c|c|}
\hline \multirow[b]{2}{*}{ Outcomes } & \multicolumn{2}{|c|}{ Intervention group } & \multicolumn{2}{|c|}{ Control group } & \multicolumn{3}{|c|}{$\begin{array}{l}\text { Adjusted difference } \\
\text { (intervention-control) }\end{array}$} & \multicolumn{3}{|c|}{$\begin{array}{l}\text { Adjusted difference with multiple } \\
\text { imputation (intervention-control) }\end{array}$} \\
\hline & No & Mean (SD) & No & Mean (SD) & $\begin{array}{c}\text { Mean }(95 \% \\
\text { Cl) }\end{array}$ & $\begin{array}{l}\text { Effect } \\
\text { size }\end{array}$ & $P$ value & Mean $(95 \% \mathrm{Cl})$ & $\begin{array}{l}\text { Effect } \\
\text { size }\end{array}$ & $P$ value \\
\hline \multicolumn{11}{|c|}{$\begin{array}{l}\text { Child sleep habits } \\
\text { questionnaire-total } \\
\text { score: }\end{array}$} \\
\hline Baseline & 121 & $57.8(8.8)$ & 121 & $59.0(7.8)$ & - & - & - & - & - & - \\
\hline 3 months & 79 & $50.1(8.3)$ & 83 & $55.1(8.6)$ & $\begin{array}{c}-6.6(-8.5 \text { to } \\
-4.6)\end{array}$ & -1.0 & $<0.001$ & $\begin{array}{c}-5.9(-7.9 \text { to } \\
-3.9)\end{array}$ & -0.8 & $<0.001$ \\
\hline 6 months & 102 & $53.2(7.5)$ & 95 & $55.9(8.8)$ & $\begin{array}{l}-3.8(-5.6 \text { to } \\
-2.0)\end{array}$ & -0.6 & $<0.001$ & $\begin{array}{c}-3.8(-5.7 \text { to } \\
-1.9)\end{array}$ & -0.6 & $<0.001$ \\
\hline
\end{tabular}

Pediatric quality of

life inventory

4.0-psychosocial

quality of life score:

\begin{tabular}{lcccccccccc}
\hline Baseline & 122 & $49.8(12.5)$ & 122 & $48.6(13.8)$ & - & - & - & - & - & - \\
\hline 3 months & 77 & $61.7(15.8)$ & 82 & $51.1(13.2)$ & $\begin{array}{c}9.4(5.6 \text { to } \\
13.2)\end{array}$ & 0.8 & $<0.001$ & $\begin{array}{c}8.9(5.2 \text { to } \\
12.6)\end{array}$ & 0.7 & $<0.001$ \\
\hline 6 months & 104 & $59.0(15.0)$ & 94 & $52.1(13.7)$ & $\begin{array}{c}6.4(2.7 \text { to } \\
10.1)\end{array}$ & 0.5 & 0.001 & $6.0(2.2$ to 9.8$)$ & 0.4 & 0.002 \\
\hline
\end{tabular}

Daily parent rating of

evening and

morning

behaviour-total

score:

\begin{tabular}{|c|c|c|c|c|c|c|c|c|c|c|}
\hline Baseline & 122 & $22.6(5.0)$ & 122 & $22.7(5.8)$ & - & - & - & - & - & - \\
\hline 3 months & 77 & $16.6(5.8)$ & 82 & $21.0(5.8)$ & $\begin{array}{c}-4.7(-6.5 \text { to } \\
-2.8)\end{array}$ & -0.8 & $<0.001$ & $\begin{array}{c}-3.8(-5.6 \text { to } \\
-2.1)\end{array}$ & -0.6 & $<0.001$ \\
\hline 6 months & 104 & $18.3(6.4)$ & 95 & $20.7(5.7)$ & $\begin{array}{c}-2.4(-4.1 \text { to } \\
-0.8)\end{array}$ & -0.4 & 0.004 & $\begin{array}{c}-2.2(-3.9 \text { to } \\
-0.5)\end{array}$ & -0.4 & 0.009 \\
\hline
\end{tabular}

Depression anxiety

stress scales-total

score:

\begin{tabular}{|c|c|c|c|c|c|c|c|c|c|c|}
\hline Baseline & 116 & $36.8(25.3)$ & 115 & $39.6(27.8)$ & - & - & - & - & - & - \\
\hline 3 months & 74 & $29.4(21.7)$ & 80 & 34.7 (26.9) & $\begin{array}{c}-5.3(-13.0 \text { to } \\
2.4)\end{array}$ & -0.2 & 0.18 & $\begin{array}{c}-5.1(-11.1 \text { to } \\
0.9)\end{array}$ & -0.3 & 0.09 \\
\hline 6 months & 101 & $31.1(23.6)$ & 90 & $33.9(28.5)$ & $\begin{array}{c}-4.9(-12.2 \text { to } \\
2.4)\end{array}$ & 0.19 & 0.19 & $\begin{array}{c}-1.7(-7.1 \text { to } \\
3.8)\end{array}$ & -0.1 & 0.55 \\
\hline
\end{tabular}

Strengths and

difficulties

questionnaire parent

report-total score

\begin{tabular}{|c|c|c|c|c|c|c|c|c|c|c|}
\hline Baseline & 122 & $22.6(5.7)$ & 122 & $21.9(5.4)$ & - & - & - & - & - & - \\
\hline 3 months & 78 & $18.6(5.0)$ & 82 & $21.4(5.4)$ & $\begin{array}{c}-3.0(-4.3 \text { to } \\
-1.7)\end{array}$ & -0.7 & $<0.001$ & $\begin{array}{c}-2.2(-3.6 \text { to } \\
-0.9)\end{array}$ & -0.5 & 0.001 \\
\hline 6 months & 103 & $18.7(5.6)$ & 95 & $21.2(5.5)$ & $\begin{array}{c}-2.1(-3.4 \text { to } \\
-0.7)\end{array}$ & -0.4 & 0.003 & $\begin{array}{c}-1.9(-3.3 \text { to } \\
-0.6)\end{array}$ & -0.4 & 0.006 \\
\hline
\end{tabular}

Strengths and

difficulties

questionnaire

teacher report-total

score:

\begin{tabular}{|c|c|c|c|c|c|c|c|c|c|c|}
\hline Baseline & 103 & $15.0(7.3)$ & 101 & $17.2(6.8)$ & - & - & - & - & - & - \\
\hline 3 months & 82 & $13.5(6.6)$ & 86 & $17.2(6.8)$ & $\begin{array}{c}-1.7(-3.4 \text { to } \\
-0.1)\end{array}$ & -0.2 & 0.04 & $\begin{array}{c}-1.8(-3.3 \text { to } \\
-0.3)\end{array}$ & -0.3 & 0.02 \\
\hline 6 months & 98 & $12.8(6.7)$ & 98 & $16.5(6.7)$ & $\begin{array}{c}-2.4(-4.3 \text { to } \\
-0.5)\end{array}$ & -0.3 & 0.01 & $\begin{array}{c}-2.0(-3.8 \text { to } \\
-0.2)\end{array}$ & -0.3 & 0.03 \\
\hline
\end{tabular}


Table 3 (continued)

\begin{tabular}{|c|c|c|c|c|c|c|c|c|}
\hline \multirow[b]{2}{*}{ Outcomes } & Intervention group & Control group & \multicolumn{3}{|c|}{$\begin{array}{l}\text { Adjusted difference } \\
\text { (intervention-control) }\end{array}$} & \multicolumn{3}{|c|}{$\begin{array}{l}\text { Adjusted difference with multiple } \\
\text { imputation (intervention-control) }\end{array}$} \\
\hline & Mean (SD) & Mean (SD) & $\begin{array}{l}\text { Mean }(95 \% \\
\quad \mathrm{Cl})\end{array}$ & $\begin{array}{l}\text { Effect } \\
\text { size }\end{array}$ & $P$ value & Mean $(95 \% \mathrm{Cl})$ & $\begin{array}{l}\text { Effect } \\
\text { size }\end{array}$ & $P$ value \\
\hline
\end{tabular}

Differences (change in symptom severity from baseline for child sleep habits questionnaire, and difference in severity for strengths and difficulties questionnaire teacher report) adjusted for children's age, sex, medication use (yes or no), total number of mental health comorbidities, parental age, parental completion of high school (yes or no), socioeconomic status (index of relative socioeconomic disadvantage).

For parent reported outcomes mean intervention versus control differences in change from baseline to outcome at three and six months adjusted for all confounding variables; for teacher reported outcomes, mean intervention versus control differences in outcome at three and six months, adjusted for baseline scores and all confounding variables. 
Table 4| Comparison of sleep variables from actigraphy between intervention and control children

\begin{tabular}{|c|c|c|c|c|}
\hline \multirow[b]{2}{*}{ Outcomes each night } & \multicolumn{2}{|c|}{ Difference in change in outcome ${ }^{*}$ (intervention-control) $\dagger$} & \multicolumn{2}{|c|}{ Difference in change in outcomeł (intervention-control)§ } \\
\hline & Mean $(95 \% \mathrm{Cl})$ & Effect size & Mean $(95 \% \mathrm{Cl})$ & Effect size \\
\hline Sleep duration (min) & $10.9(-19.0$ to 40.8$)$ & 0.2 & $9.9(-16.3$ to 36.1$)$ & 0.3 \\
\hline Sleep efficiency (\%) & $-1.6(-5.2$ to 1.9$)$ & -0.3 & $-0.1(-0.2$ to 2.6$)$ & -0.03 \\
\hline Wake after sleep onset (min) & $1.5(-16.9$ to 19.9$)$ & 0.05 & $3.2(-20.7$ to 27.0$)$ & 0.1 \\
\hline
\end{tabular}

${ }^{*}$ From baseline to three months.

†Intervention $\mathrm{n}=25$; usual care $\mathrm{n}=29$.

¥From baseline to six months.

§Intervention $n=17$; usual care $n=20$. 


\section{Figure}

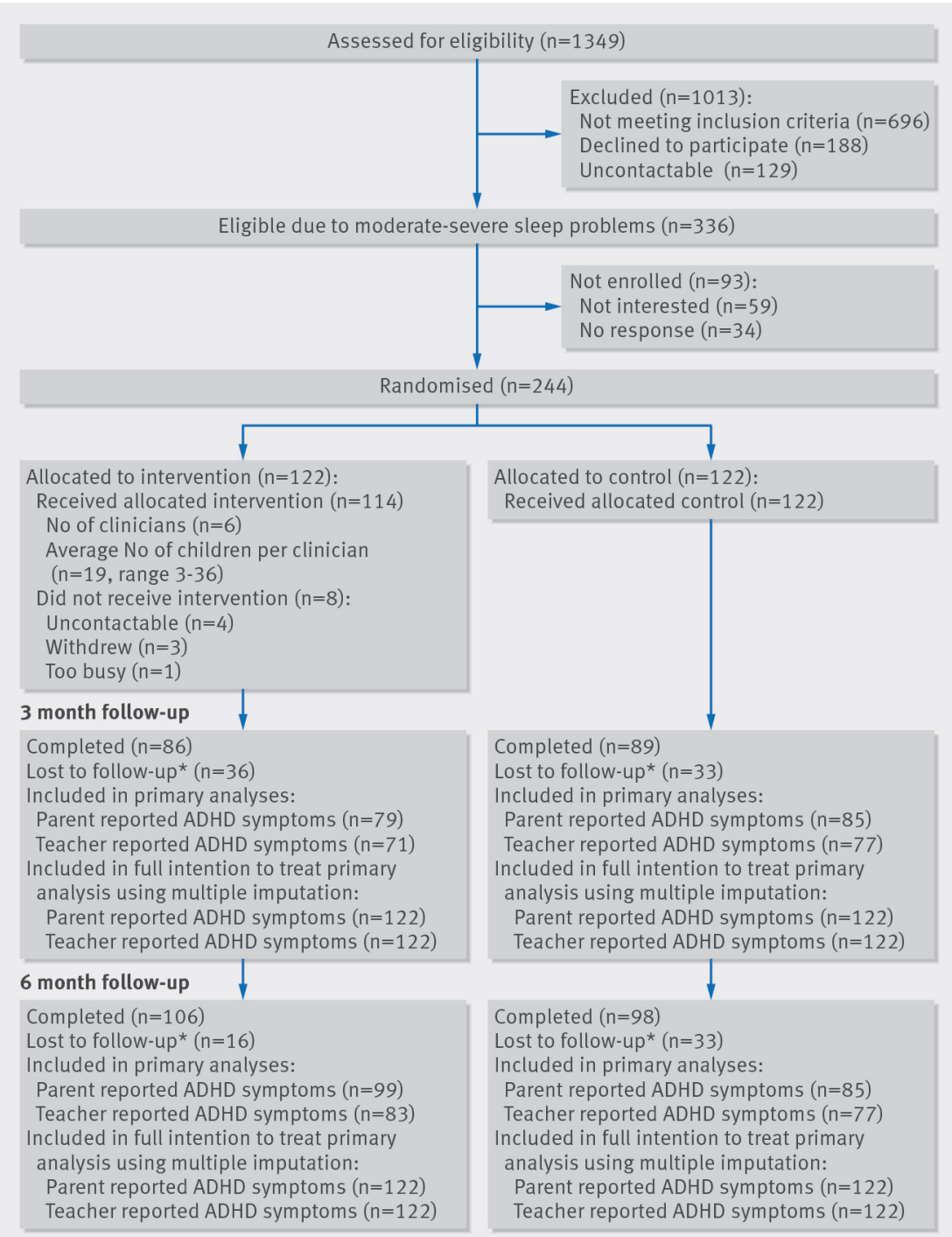

Flow of families through study. *Failed to return follow-up questionnaires. ADHD=attention deficit hyperactivity disorder 